illnesses for the 2013-14 influenza season. CDC Health Alert Network. December 24, 2013 [accessed 2014 Jan 10]. Available from: http://emergency.cdc.gov/HAN/han00359. asp

10. Centers for Disease Control and Prevention. Estimated influenza illnesses and hospitalizations averted by influenza vaccination United States, 2012-13 influenza season. MMWR Morb Mortal Wkly Rep 2013;62:997-1000.

11. Castilla J, Godoy P, Domínguez A, Martínez-Baz I, Astray J, Martín V, Delgado-Rodríguez M, Baricot M, Soldevila N, Mayoral JM, et al.; CIBERESP Cases and Controls in Influenza Working Group Spain. Influenza vaccine effectiveness in preventing outpatient, inpatient, and severe cases of laboratory-confirmed influenza. Clin Infect Dis 2013;57:167-175.

12. Chartrand C, Leeflang MM, Minion J, Brewer T, Pai M. Accuracy of rapid influenza diagnostic tests: a meta-analysis. Ann Intern Med 2012;156:500.

13. Blyth CC, Iredell JR, Dwyer DE. Rapid-test sensitivity for novel swine-origin influenza A (H1N1) virus in humans. N Engl J Med 2009;361:2493.

14. Singh K, Vasoo S, Stevens J, Schreckenberger P, Trenholme G. Pitfalls in diagnosis of pandemic (novel) A/H1N1 2009 influenza. J Clin Microbiol 2010;48:1501-1503.

Copyright (c) 2014 by the American Thoracic Society

\section{Occupational Exposure to Vapors, Gases, Dusts, and Fumes Is Associated with Small Airways Obstruction}

\section{To the Editor:}

Various studies have shown that occupational exposures to vapors, gases, dusts, and fumes or their composite measure (VGDF) negatively affect $\mathrm{FEV}_{1}$ and the $\mathrm{FEV}_{1} / \mathrm{FVC}$ ratio, indicating obstruction of predominantly the large airways (1-3). Recently we have shown that occupational exposure to pesticides is associated with substantial losses of large airway function in the general population (3). The negative effects of occupational exposures on the level of lung function were generally more pronounced in everthan in never-smokers, suggesting that cigarette smoke-induced damage increases the susceptibility of the airways to other exposures (3). In addition to interest in large airways obstruction, there is considerable renewed interest in obstruction of the small airways, since small airways obstruction is one of the three main phenotypes of chronic obstructive pulmonary disease (COPD) $(4,5)$.

Supported by research school GUIDE, University of Groningen, University Medical Center Groningen (K.d.J.). The LifeLines cohort study was supported by the Dutch Ministry of Health, Welfare and Sport; the Ministry of Economic Affairs, Agriculture and Innovation; the province of Groningen; the European Union (regional development fund); the Northern Netherlands Provinces (SNN); the Netherlands Organization for Scientific Research (NWO); University Medical Center Groningen (UMCG); University of Groningen, de Nierstichting (the Dutch Kidney Foundation); and the Diabetes Fonds (the Diabetic Foundation).

Author Contributions: K.d.J. participated in the study design, analysis and interpretation of the data, and drafting of the manuscript, tables and figures. H.M.B., D.S.P., and J.M.V. obtained funding, determined the study design, participated in the analysis and interpretation of data, and critically supervised writing of the manuscript. H.K. and R.V. designed and provided the ALOHA+ JEM and participated in writing of the manuscript. All authors approved the final version of the manuscript.
Thus far, only one general population-based study in 1,735 individuals has shown associations of occupational exposure to biological dust with forced expiratory flow between 25\% and 75\% of FVC ( $\left.\mathrm{FEF}_{25-75}\right)$, an indicator of small airways obstruction (1). In addition, some small-scale studies in specific populations have shown negative effects of specific occupational exposures on the small airways, like nonasbestos mineral dusts (6), welding fumes $(7,8)$, and pesticide exposure $(9,10)$. However, these studies included individuals with large airways obstruction, or individuals with reduced FVC that may affect levels of $\mathrm{FEF}_{25-75}$ values, and were thus not specifically investigating small airway obstruction.

We used data from 11,851 participants, 9,876 without large airways obstruction, of the LifeLines population for which we have estimated job-specific exposure to the composite measure VGDF (and separately to subcategories biological dust, mineral dust, gases, and fumes) and exposure to pesticides in general (and separately to subcategories herbicides and insecticides) as no, low, and high (0/1/ 2) exposure using the ALOHA + job exposure matrix (JEM) (3). We assessed associations between occupational exposures and $\mathrm{FEF}_{25-75}(\mathrm{ml} / \mathrm{s})$ levels using linear regression with adjustment for sex, age, height, weight, current smoking, former smoking, and (log) pack-years. Because of substantial co-exposure between the specific occupational agents, we additionally adjusted the analyses on the composite measure VGDF, biological dust, mineral dust, gases, and fumes for co-exposure to pesticides, and conversely the analyses on pesticides, herbicides, and insecticides were adjusted for co-exposure to the composite measure VGDF (3).

Of the total of 11,851 subjects, $42 \%$ were male, median age being 47 years (range, 18-89 yr), 57\% being ever-smokers (median number of pack-years, 10; range, $0-100)$. Mean $\mathrm{FEV}_{1} \%$ predicted was $102 \%, \mathrm{FEV}_{1} / \mathrm{FVC} 76 \%$, and $\mathrm{FEF}_{25-75} 2.9 \mathrm{~L} / \mathrm{s}$ (78\% predicted). Subjects without large airways obstruction $\left(\mathrm{FEV}_{1} / \mathrm{FVC} \geqslant 70 \%\right.$, $\mathrm{FEV}_{1} \geqslant 80 \% ; \mathrm{n}=9,876 ; 83 \%$ ) had a median age of 46 years (range, $18-89 \mathrm{yr}$ ), $40 \%$ being male and $54 \%$ being ever-smokers (median number of pack-years, 9; range, $0-84$ ). In both groups, about 11 percent of the subjects were highly exposed to the composite measure VGDF, whereas high exposure to pesticides in general was less common (1\%; Table 1$)$.

Exposure to the composite measure VGDF, and to the subcategories biological dust and gases and fumes, was associated with lower $\mathrm{FEF}_{25-75}$ levels (Table 1). These associations remained present when we restricted our analysis to subjects without large airways obstruction (Table 1). Moreover, findings were similar in ever- and in never-smokers (Figure 1) and when adjusted for FVC. Occupational exposure to pesticides in general and to the subcategories herbicides and insecticides tended to be associated with lower $\mathrm{FEF}_{25-75}$ in the whole group, yet these associations largely disappeared when the analysis was restricted to subjects without large airways obstruction (Table 1).

It is known that occupational exposure to vapors, gases, dusts, and fumes affects large airway function and increases the risk for spirometry-defined COPD $(1-3,11,12)$. With the present letter we add to this knowledge by showing that the small airways are affected by occupational exposure to the composite measure VGDF, and also to the subcategories biological dust, gases, and fumes. Importantly, we find these associations in subjects with normal $\mathrm{FEV}_{1} / \mathrm{FVC}$ and $\mathrm{FEV}_{1} \%$ predicted values as well, indicating 
Table 1: Associations between Occupational Exposures and Level of $\mathrm{FEF}_{25-75}(\mathrm{ml} / \mathrm{s})$ for the Whole Sample and for Subjects without Large Airways Obstruction ( $\left.\mathrm{FEV}_{1} / \mathrm{FVC} \geqslant 70 \%, \mathrm{FEV}_{1} \geqslant 80 \%\right)$

\begin{tabular}{|c|c|c|c|c|c|c|}
\hline \multirow[b]{3}{*}{ Exposure* } & \multirow[b]{3}{*}{ b $(95 \% \mathrm{Cl})$} & \multicolumn{3}{|c|}{ FEF $_{25-75}(\mathrm{ml} / \mathrm{s})$} & & \\
\hline & & \multicolumn{2}{|c|}{ All $(n=11,851)$} & \multicolumn{3}{|c|}{ Without large airways obstruction $(n=9,876)$} \\
\hline & & $P$ Value & n (\%) & b $(95 \% \mathrm{Cl})$ & $P$ Value & n (\%) \\
\hline \multicolumn{7}{|l|}{ VGDF } \\
\hline Nonexposed & Ref. & & $6,534(55)$ & Ref. & & $5,513(56)$ \\
\hline $\begin{array}{l}\text { Low } \\
\text { High }\end{array}$ & $\begin{array}{r}-47(-83 ;-10) \\
-157(-220 ;-93)\end{array}$ & $\begin{array}{r}0.012 \\
<0.001\end{array}$ & $\begin{array}{l}3,985(34) \\
1,332(11)\end{array}$ & $\begin{array}{r}-39(-74 ;-4) \\
-102(-166 ;-39)\end{array}$ & $\begin{array}{l}0.031 \\
0.001\end{array}$ & $\begin{array}{l}3,325(34) \\
1,038(11)\end{array}$ \\
\hline \multicolumn{7}{|l|}{ Biological dust } \\
\hline Nonexposed & Ref. & & $8,127(69)$ & Ref. & & $6,787(69)$ \\
\hline Low & $-17(-56 ; 22)$ & 0.389 & $3,256(28)$ & $-18(-55 ; 19)$ & 0.343 & $2,707(27)$ \\
\hline High & $-84(-186 ; 17)$ & 0.104 & $468(4)$ & $-143(-244 ;-43)$ & 0.005 & $382(4)$ \\
\hline \multicolumn{7}{|l|}{ Mineral dust } \\
\hline Nonexposed & Ref. & & $9,389(79)$ & Ref. & & $7,907(80)$ \\
\hline Low & $-62(-109 ;-15)$ & 0.009 & $1,924(16)$ & $-38(-83 ; 8)$ & 0.104 & $1,551(16)$ \\
\hline High & $-69(-162 ; 24)$ & 0.148 & $538(5)$ & $12(-79 ; 104)$ & 0.790 & 418 (4) \\
\hline \multicolumn{7}{|l|}{ Gases/Fumes } \\
\hline Nonexposed & Ref. & & $7,007(59)$ & Ref. & & $5,905(60)$ \\
\hline Low & $-51(-88 ;-14)$ & 0.006 & 4,159 (35) & $-46(-18 ;-10)$ & 0.011 & $3,446(35)$ \\
\hline High & $-137(-212 ;-62)$ & $<0.001$ & $685(6)$ & $-59(-134 ; 15)$ & 0.118 & $525(5)$ \\
\hline \multicolumn{7}{|l|}{ All pesticides } \\
\hline Nonexposed & Ref. & & $11,369(96)$ & Ref. & & $9,494(96)$ \\
\hline Low & $-73(-174 ; 29)$ & 0.162 & $370(3)$ & $-115(-214 ;-16)$ & 0.023 & $303(3)$ \\
\hline High & $-93(-270 ; 83)$ & 0.300 & $112(0.9)$ & $0(-184 ; 184)$ & 0.999 & $79(0.8)$ \\
\hline \multicolumn{7}{|l|}{ Herbicides } \\
\hline Nonexposed & Ref. & & $11,680(99)$ & Ref. & & $9,754(99)$ \\
\hline Low & $-96(-258 ; 65)$ & 0.243 & $132(1)$ & $-105(-267 ; 57)$ & 0.204 & $101(1)$ \\
\hline High & $-193(-485 ; 99)$ & 0.195 & $39(0.3)$ & $218(-131 ; 567)$ & 0.220 & $21(0.2)$ \\
\hline \multicolumn{7}{|l|}{ Insecticides } \\
\hline Nonexposed & Ref. & & $11,425(96)$ & Ref. & & $9,540(97)$ \\
\hline Low & $-71(-181 ; 39)$ & 0.206 & $315(3)$ & $-114(-221 ;-7)$ & 0.036 & 258 (3) \\
\hline High & $-90(-267 ; 87)$ & 0.320 & $111(0.9)$ & $13(-172 ; 198)$ & 0.890 & $78(0.8)$ \\
\hline
\end{tabular}

Definition of abbreviation: VGDF = the composite measure of vapors, gases, dusts, and fumes.

Statistically significant associations are depicted in bold ( $P$ values $<0.05)$.

*Occupational exposures (no/low/high) were estimated based on job title and function using the ALOHA+ job exposure matrix. Nonexposed subjects were assigned as reference category (Ref).

The linear regression model was adjusted for sex, age, height, weight, current smoking, former smoking, and (log) pack-years. The analyses on biological dust, mineral dust, gases and fumes, and the composite measure VGDF were additionally adjusted for pesticide exposure, whereas the analyses on pesticides, herbicides, and insecticides were additionally adjusted for exposure to the composite measure VGDF.

that effects of exposure to vapors, gases, dusts, and fumes on the small airways are a primary response and independent from effects on the large airways. The observed associations were found to be independent of smoking habits, which is in contrast to our previous findings on large airways obstruction, where we found significant differences between ever-smokers

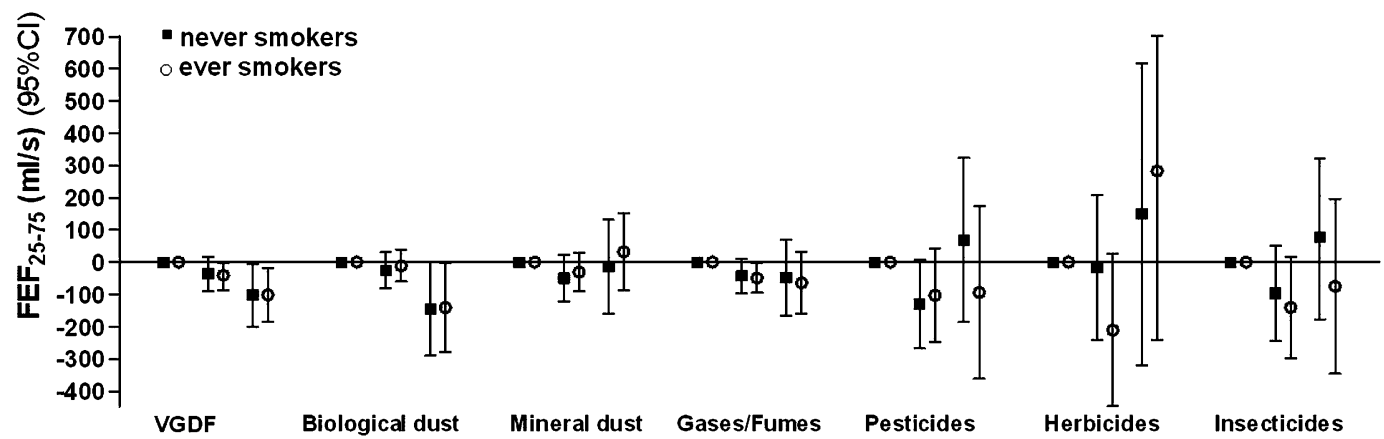

Figure 1. Associations between occupational exposures and level of $\mathrm{FEF}_{25-75}(\mathrm{ml} / \mathrm{s})$ for subjects without large airways obstruction $\left(\mathrm{FEV} \mathrm{V}_{1} / \mathrm{FVC} \geqslant 70 \%\right.$, $\mathrm{FEV}_{1} \geqslant 80 \%$ ), stratified by smoking status (never/ever). Associations are shown for no (reference: set on 0), low, and high exposure to the composite measure vapors, gases, dusts, and fumes (VGDF), and the subcategories biological dust, mineral dust, gases and fumes, pesticides in general, and the subcategories herbicides and insecticides. 
and never-smokers (3). The lack of effects of smoking on small airways function in interaction with occupational exposure is in line with a previous study investigating biological dust (1).

Although exposure to pesticides was strongly and consistently associated with level of $\mathrm{FEV}_{1}$ in our previous cross-sectional study (3), the trend for an association with $\mathrm{FEF}_{25-75}$ did not reach statistical significance and disappeared when analyses were restricted to subjects without large airways obstruction. In line with our findings, a study from Sri Lanka found no significant reduction in $\mathrm{FEF}_{25-75}$ levels of farmers exposed to pesticides, whereas there was a significant effect on $\mathrm{FEV}_{1}$ and FVC levels (13). It may be that the aerodynamic diameter of the pesticide aerosols results in deposition mainly in the larger airways. A study assessing different types of pesticides and agricultural application methods showed that aerosols had a median aerodynamic diameter ranging from 4 to $16 \mu \mathrm{m}$ (14), whereas for example fibrous dust has an aerodynamic diameter less than $3 \mu \mathrm{m}$ and the majority of welding aerosols have an aerodynamic diameter less than $1 \mu \mathrm{m}$ (15).

In conclusion, with the current study we show that occupational exposure to vapors, gases, dusts, and fumes induces small airways obstruction independently of large airways obstruction in both ever- and never-smokers. Loss and narrowing of the small airways is seen in patients with mild COPD even before the onset of emphysematous destruction, and becomes increasingly evident in severe COPD (4). Therefore, small airway obstruction should be taken into account when monitoring respiratory health of workers that are exposed to vapors, gases, dusts, and fumes.

\section{Author disclosures are available with the text of this letter at} www.atsjournals.org.

Participants in the LifeLines Cohort Study: B. Z. Alizadeh (Department of Epidemiology, University of Groningen, University Medical Center Groningen, Groningen, The Netherlands), R. A. de Boer (Department of Cardiology, University of Groningen, University Medical Center Groningen, Groningen, The Netherlands), H. M. Boezen (Department of Epidemiology, University of Groningen, University Medical Center Groningen, Groningen, The Netherlands), M. Bruinenberg (LifeLines Cohort Study, University of Groningen, University Medical Center Groningen, Groningen, The Netherlands), L. Franke (Department of Genetics, University of Groningen, University Medical Center Groningen, Groningen, The Netherlands), P. van der Harst (Department of Cardiology, University of Groningen, University Medical Center Groningen, Groningen, The Netherlands), H. L. Hillege (Department of Epidemiology and Department of Cardiology, University of Groningen, University Medical Center Groningen, Groningen, The Netherlands), M. M. van der Klauw (Department of Endocrinology, University of Groningen, University Medical Center Groningen, Groningen, The Netherlands), G. Navis (Department of Internal Medicine, Division of Nephrology, University of Groningen, University Medical Center Groningen, Groningen, The Netherlands), J. Ormel (Interdisciplinary Center of Psychopathology of Emotion Regulation [ICPE], Department of Psychiatry, University of Groningen, University Medical Center Groningen, Groningen, The Netherlands), D. S. Postma (Department of Pulmonology, University of Groningen, University Medical Center Groningen, Groningen, The Netherlands), J. G. M. Rosmalen (Interdisciplinary Center of Psychopathology of Emotion Regulation [ICPE], Department of Psychiatry, University of Groningen, University Medical Center Groningen, Groningen, The Netherlands), J. P. Slaets (University Center for Geriatric Medicine, University of Groningen, University Medical Center Groningen, Groningen, The Netherlands), H. Snieder (Department of Epidemiology, University of Groningen, University Medical Center Groningen,

Groningen, The Netherlands), R. P. Stolk (Department of Epidemiology,
University of Groningen, University Medical Center Groningen, Groningen, The Netherlands), B. H. R. Wolffenbuttel (Department of Endocrinology, University of Groningen, University Medical Center Groningen, Groningen, The Netherlands), and C. Wijmenga (Department of Genetics, University of Groningen, University Medical Center Groningen, Groningen, The Netherlands).

Kim de Jong, M.Sc.

H. Marike Boezen, Ph.D.

Hans Kromhout, Ph.D.

Roel Vermeulen, Ph.D.

Judith M. Vonk, Ph.D.

Dirkje S. Postma, M.D., Ph.D.

and the LifeLines cohort study

University of Groningen, University Medical Center Groningen

Groningen, The Netherlands

and

University of Utrecht

Utrecht, The Netherlands

\section{References}

1. Sunyer J, Kogevinas M, Kromhout $H$, Antó JM, Roca J, Tobias A, Vermeulen R, Payo F, Maldonado JA, Martinez-Moratalla J, et al. Pulmonary ventilatory defects and occupational exposures in a population-based study in Spain. Spanish Group of the European Community Respiratory Health Survey. Am J Respir Crit Care Med 1998;157:512-517.

2. Zock JP, Sunyer J, Kogevinas M, Kromhout H, Burney P, Antó JM. Occupation, chronic bronchitis, and lung function in young adults: an international study. Am J Respir Crit Care Med 2001;163: 1572-1577.

3. de Jong K, Boezen HM, Kromhout H, Vermeulen R, Postma DS, Vonk JM; LifeLines Cohort study. Pesticides and other occupational exposures are associated with airway obstruction: the LifeLines cohort study. Occup Environ Med 2014;71:88-96.

4. McDonough JE, Yuan R, Suzuki M, Seyednejad N, Elliott WM, Sanchez PG, Wright AC, Gefter WB, Litzky L, Coxson HO, et al. Small-airway obstruction and emphysema in chronic obstructive pulmonary disease. N Engl J Med 2011;365:1567-1575.

5. van den Berge M, ten Hacken NH, Cohen J, Douma WR, Postma DS. Small airway disease in asthma and COPD: clinical implications. Chest 2011;139:412-423.

6. Churg A, Wright JL. Bronchiolitis caused by occupational and ambient atmospheric particles. Semin Respir Crit Care Med 2003;24:577-584.

7. Kilburn $\mathrm{KH}$, Warshaw RH. Pulmonary functional impairment from years of arc welding. Am J Med 1989;87:62-69.

8. Hjortsberg $U$, Orbaek P, Arborelius M Jr. Small airways dysfunction among non-smoking shipyard arc welders. Br J Ind Med 1992;49:441-444.

9. Hernández AF, Casado I, Pena G, Gil F, Villanueva E, Pla A. Low level of exposure to pesticides leads to lung dysfunction in occupationally exposed subjects. Inhal Toxicol 2008;20:839-849.

10. Salameh P, Waked M, Baldi I, Brochard P. Spirometric changes following the use of pesticides. East Mediterr Health $J$ 2005;11: 126-136.

11. Matheson MC, Benke G, Raven J, Sim MR, Kromhout H, Vermeulen R, Johns DP, Walters EH, Abramson MJ. Biological dust exposure in the workplace is a risk factor for chronic obstructive pulmonary disease. Thorax 2005;60:645-651.

12. Mehta A, Miedinger $D$, Keidel D, Bettschart R, Bircher $A$, Bridevaux $P$, Curjuric I, Kromhout H, Rochat T, Rothe T, et al.; SAPALDIA Team. Occupational exposure to dusts, gases and fumes and incidence of COPD in SAPALDIA. Am J Respir Crit Care Med 2012;185: 1292-1300.

13. Peiris-John RJ, Ruberu DK, Wickremasinghe AR, van-der-Hoek W. Low-level exposure to organophosphate pesticides leads to restrictive lung dysfunction. Respir Med 2005;99:1319-1324.

14. Bémer D, Fismes J, Subra I, Blachère V, Protois JC. Pesticide aerosol characteristics in the vicinity of an agricultural vehicle cab during application. J Occup Environ Hyg 2007;4:476-482. 
15. Berlinger B, Benker N, Weinbruch S, L'Vov B, Ebert M, Koch W, Ellingsen DG, Thomassen Y. Physicochemical characterisation of different welding aerosols. Anal Bioanal Chem 2011;399:1773-1780.

Copyright () 2014 by the American Thoracic Society

\section{Successful Management of a Chronic, Refractory Bronchopleural Fistula with Endobronchial Valves followed by Talc Pleurodesis}

To the Editor:

Lymphangioleiomyomatosis (LAM) is a rare, neoplastic lung disease that affects women more often than men, and is associated with cystic destruction of the lung $(1,2)$. Over $65 \%$ of patients with LAM develop pneumothorax during the course of their illness, followed by two or more recurrences, on average $(3,4)$. An attempt at pleural symphysis with the first pneumothorax is therefore recommended, despite pleurodesis failure rates that exceed those of most other chronic lung diseases (3). The following case describes the use of one-way endobronchial valves to treat a persistent bronchopleural fistula that had failed to resolve after multiple prior medical and surgical management approaches.

The patient was a 39 -year-old nonsmoking female physician who developed a spontaneous right pneumothorax. Computed tomography (CT) scanning of the chest revealed a large collection of air in the right anterior hemithorax, and numerous large round cysts varying in size from $3 \mathrm{~mm}$ to $4.6 \mathrm{~cm}$ (Figure 1A). Because of the unusual cyst dimensions, and an atypical basilar and peripheral distribution, the patient was initially thought to have Birt-HoggDubé syndrome, but genetic testing for folliculin mutations was negative. Her pulmonary function tests were normal, and the pneumothorax was treated with simple chest tube drainage. She developed a recurrent right-sided pneumothorax 6 months later, treated initially for 2 days with small-bore chest tube drainage as an inpatient and continuing for 5 days after discharge with Heimlich valve-regulated drainage. She developed shortness of breath and decreased exercise tolerance 3 days after the chest tube was removed. She was found to have a right-sided pneumothorax and

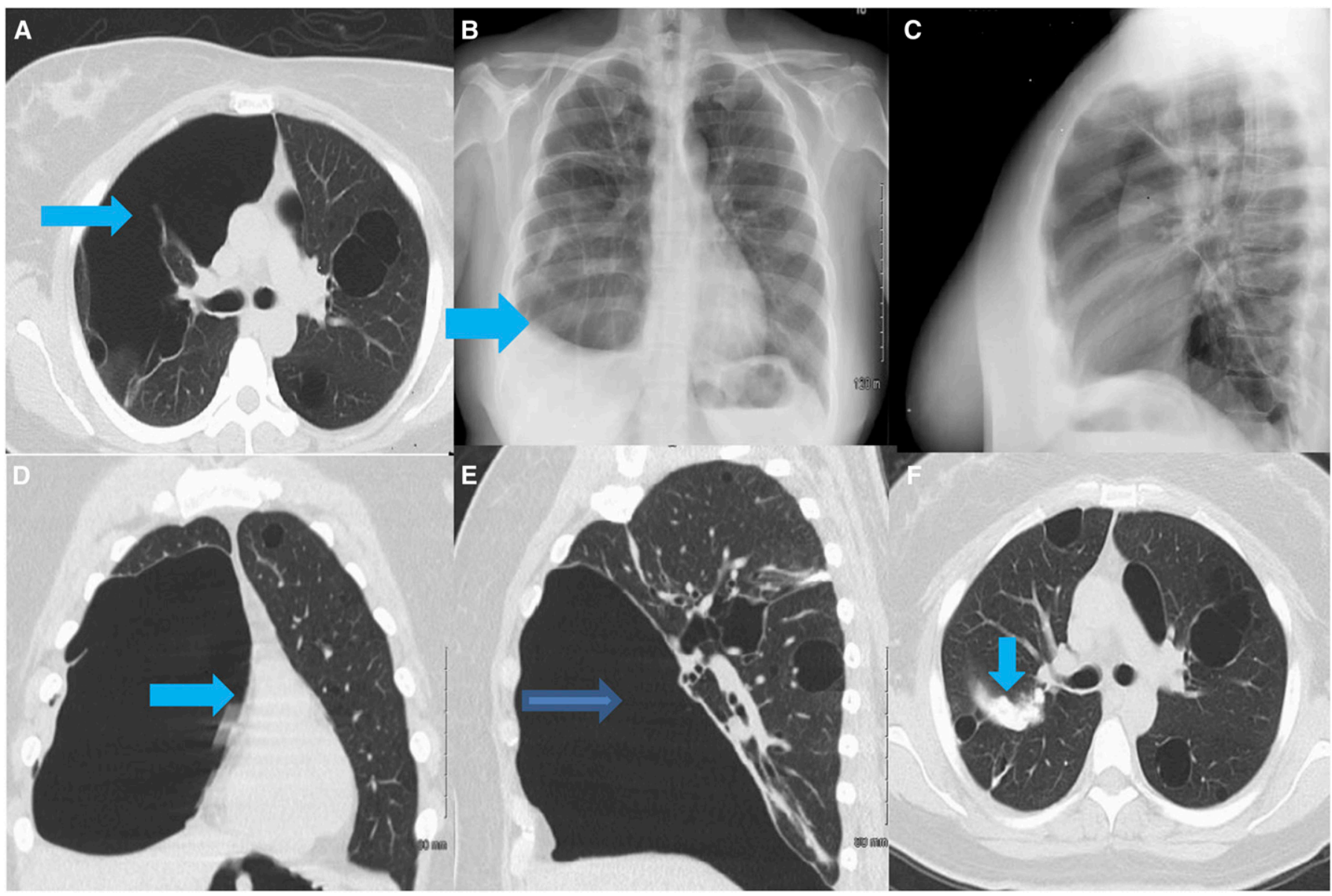

Figure 1. (A) Large right-sided pneumothorax (arrow) and multiple cystic lesions (arrow) were later confirmed to be due to lymphangioleiomyomatosis Recurrent right-sided pneumothorax presented with dyspnea on exertion and reduction in forced vital capacity. Posteroanterior $(B)$ and lateral $(C)$ chest radiograph showed a right pleural effusion (arrow), but pneuomothorax was not readily apparent. Coronal $(D)$ and sagittal $(E)$ images from a computed tomography $(\mathrm{CT})$ scan of the chest revealed a large anterior pleural air collection $(D$, arrow), and leftward mediastinal shift consistent with tension pneumothorax ( $E$, arrow). ( $F$ ) CT scan showing complete resolution of right-sided pneuomothorax 3 months after second endobronchial valve replacement and talc pleurodesis. A collection of talc within the fissure is visible (arrow). 